\section{Singapore hosts 10th International Conference on Materials for Advanced Technologies}

$\mathrm{T}$ he International Conference on Materials for Advanced Technologies (ICMAT) held its 10th edition of the conference series June 23-28 in Singapore. The first nine conferences in this series were held in Singapore, attracting a total of more than 23,000 participants, with a large international representation.

One of the unique features of the ICMAT series is the attendees: 25 Nobel laureates, hundreds of distinguished plenary and keynote speakers, and a significant number of students. ICMAT is hailed as one of the largest conferences for materials research, with this year's meeting including attendees from 52 countries. The conference, thus, offers a chance for participants to have insights in their field of research with an overview on a worldwide scale. ICMAT 2019 hosted 45 technical symposia, which provided an ideal platform to promote interdisciplinary and international collaborations.

The focus of the conference was to investigate material and macroscopic property correlation for various applications. Theoretical and applied fundamentals of materials science, nanoscience, and nanotechnology were discussed, along with themes in synthesis, characterization, simulation, and applications of traditional fields, namely functional materials, energy materials, and photonics. New topics were introduced, including materials design, additive manufacturing, biomaterials, and wearable technology.

Swee Keat Heng, Deputy Prime Minister and Minister for Finance (Singapore), served as a guest of honor and narrated Singapore's journey in the field of materials science and its impact on the economy. The visionary approach of Singapore almost

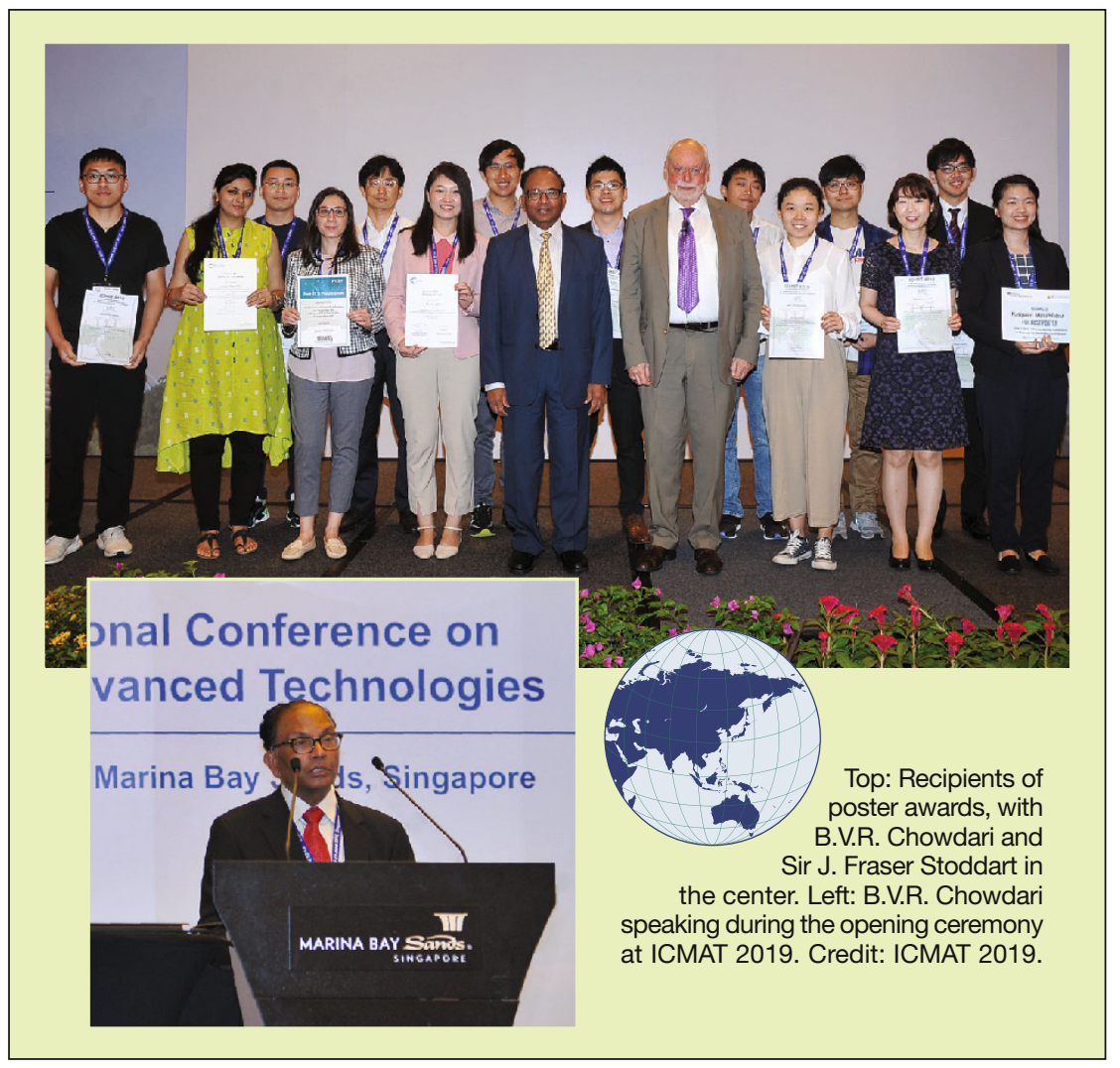

three decades ago has made manufacturing the country's largest export sector, driven essentially by advanced materials technologies. Heng emphasized the technological changes that disrupt industries and at the same time create new opportunities: "We can either sink under the waves, or ride the rising tide of technological advances together."

At this year's meeting, the Materials Research Society of Singapore (MRS-S) gave back to the community by donating to the Nanyang Technological University (NTU) and the National University of Singapore, and supporting materials science researchers of the region to promote collaborative work at the universities. MRS-S and the Materials Research Society (MRS) jointly organized a special symposium in honor of C.N.R. Rao, the first Asian to receive the prestigious MRS Von Hippel Award.

The conference featured Nobel laureate public lectures at NTU Singapore by Sirs Andre Geim and J. Fraser Stoddart and plenary lectures by Klaus von Klitzing, Hiroshi Amano, and Subra Suresh. The focus of the forum on women in science, engineering and technology highlighted opportunities and explained some of the pitfalls for females as engineers and researchers. Similarly, the forum for young researchers discussed the challenges faced in finding jobs and venturing into startup companies. Chan Lai Fung, chairman of the Agency for Science, Technology and Research (A*STAR) and guest of honor, highlighted the importance of innovation and international research collaborations in her presentation.

ICMAT has become an important platform to share, discuss, and expand knowledge in science and technology, with materials science research at the center. It also provides attendees with an opportunity to visit and meet professors and scientists from world-class universities and research institutes.

B.V.R. Chowdari
President, MRS Singapore
Chairman, ICMAT 2019

Shweta Agarwala Aarhus University, Denmark 